\title{
Comparison of immunohistochemical analysis on sinus augmentation using demineralized tooth graft and bovine bone
}

\author{
Dong-Seok Sohn ${ }^{1}$, Ji-Rak Kim², Hyung-Gyun Kim¹, Hyun-Suk Choi ${ }^{3}$, Yong-Suk Moon ${ }^{4}$ \\ ${ }^{1}$ Department of Dentistry and Oral and Maxillofacial Surgery, School of Medicine, Daegu Catholic University, \\ ${ }^{2}$ Department of Oral Medicine, School of Dentistry, Kyungpook National University, ${ }^{3}$ Department of Dentistry and Prosthodontics, \\ School of Medicine, Daegu Catholic University, ${ }^{4}$ Department of Anatomy, School of Medicine, Daegu Catholic University, Daegu, Korea
}

\begin{abstract}
J Korean Assoc Oral Maxillofac Surg 2021;47:269-278)
Objectives: The purpose of this animal research was to compare bone regeneration in augmented rabbit maxillary sinuses treated with demineralized particulate human-tooth graft and anorganic bovine bone by immunohistochemical analysis.

Materials and Methods: Piezoelectric bilateral sinus augmentation was performed in eight adult rabbits. In the control group, anorganic bovine was grafted in the maxillary sinus following elevation of the sinus membrane. In the experimental group, demineralized human particulate tooth bone was grafted in the sinus. Bone regeneration in augmented sinuses was evaluated by immunohistochemical analysis using various markers of osteoprogenitor cells.

Results: The number of bromodeoxyuridine-labeled cells was significantly higher in the experimental group than in the control group at eight weeks. The immunoreactivity of proliferating-cell nuclear antigen was increased slightly in the experimental group relative to the control group at eight weeks. Other bone markers were expressed equally in the two groups.

Conclusion: In the rabbit maxillary sinus, higher osteoinduction was correlated with demineralized human particulate tooth bone grafting than with anorganic bovine grafting.
\end{abstract}

Key words: Maxillary sinus lift, Demineralized tooth bone, Replaceable bony window, Immunohistochemical assay

[paper submitted 2021. 3. 15 / revised 2021. 6. 14 / accepted 2021. 7. 8]

\section{Introduction}

Pneumatized maxillary sinus is a challenging site for dental implants due to the insufficient bone quantity typically present. Maxillary sinus augmentation is the most common surgical technique for vertical augmentation of the atrophic posterior maxilla ${ }^{1,2}$. The new compartment created between the floor of the maxillary sinus and the elevated sinus membrane is typically filled with osteoinductive or osteoconductive bone graft to maintain space for new bone formation for last several decades ${ }^{3-8}$. Autogenous bone grafting has been

\section{Yong-Suk Moon}

Department of Anatomy, School of Medicine, Daegu Catholic University, 33 Duryugongwon-ro 17-gil, Nam-gu, Daegu 42472, Korea

TEL: +82-53-650-4458

E-mail: essay2ndtree@daum.net

ORCID: https://orcid.org/0000-0001-5405-8919

(c) This is an open-access article distributed under the terms of the Creative Commons Attribution Non-Commercial License (http://creativecommons.org/ licenses/by-nc/4.0/), which permits unrestricted non-commercial use, distribution, and reproduction in any medium, provided the original work is properly cited.

Copyright (C) 2021 The Korean Association of Oral and Maxillofacial Surgeons. widely accepted for sinus augmentation since it boasts both osteoinductivity and osteoconductivity. However, due to its drawbacks, including the morbidity of a second surgical site and prolonged operation time, various bone substitutes have been trialed for sinus augmentation ${ }^{9,10}$. These bone substitutes are osteoconductive and mainly function as space makers in the sinus.

As an alternative to osteoinductive autologous bone graft, demineralized tooth bone has been accepted for ridge and sinus augmentation because it has similar components to human bone and is known to release diverse osteoinductive growth factors during the healing period ${ }^{11,12}$. Autologous extracted teeth have been utilized for ridge and sinus augmentation, after an appropriate decalcification and sterilization process, in block or particulate form ${ }^{13-15}$. However, comparative immunohistochemical research on bone reformation in the maxillary sinus with osteoconductive bovine bone and osteoinductive demineralized particulate tooth bone is rare. The aim of this study was to compare bone reformation after maxillary sinus augmentation using bovine bone and demin- 
eralized particulate tooth bone by means of immunohistochemical analysis.

\section{Materials and Methods}

\section{Preparation of demineralized tooth bone (dTB)}

Extracted permanent human teeth without caries or restorations were collected, and any soft tissue that remained attached was removed using a rotary instrument with coolant. All steps, including demineralization, washing were processed in a vacuum-ultrasonic device (VacuaSonic System; CosmoBioMedicare, Seoul, Korea). After sterilization of the teeth with sterilization reagent (peracetic acid ethanol solution) in a vacuum-ultrasonic device, the teeth were crushed into powder with particles measuring 0.8 to $1.0 \mathrm{~mm}$ in size on the experimental day, and demineralization using $0.6 \mathrm{~N}$ of hydrochloride was performed for 15 minutes under vacuum compression and ultrasonic vibration in a vacuum-ultrasonic device. The demineralized particulate tooth bone was washed with phosphate-buffered saline (PBS), sterilized with sterilization reagent, and washed again with PBS and distilled water.

\section{Surgical procedures}

Eight adult male New Zealand white rabbits weighing from 2.8 to $3.2 \mathrm{~kg}$ (mean, $3.0 \mathrm{~kg}$ ) were included in the present study as experimental animals. This study was approved by the Animal Care and Use Committee at the Catholic University Medical Center of Daegu (DCIAFCR-160705-3-Y). Four rabbits were placed in each group, and all rabbits underwent the same surgical procedure under general anesthesia with a combination of $30 \mathrm{mg} / \mathrm{kg}$ of ketamine (Ketalar; Yuhan, Seoul, Korea) and $10 \mathrm{mg} / \mathrm{kg}$ of xylazine (Rompun; Bayer Korea, Seoul, Korea) administered intramuscularly. Before making an incision on the nasal dorsum, about $0.5 \mathrm{~mL}$ of lidocaine with 1:100,000 epinephrine was injected subcutaneously along the midline of the nasal dorsum. Skin and periosteal incisions were created with a 15-c blade at the middle of the nasal dorsum to expose the nasal bone and nasoincisional suture line. A rectangular replaceable bony window, measuring about $5 \mathrm{~mm} \times 10 \mathrm{~mm}$, was created with a thin saw insert (S-Saw; Bukbu Dental, Daegu, Korea) connected to a piezoelectric device (Surgybone; Silfradent, Sofia, Italy). Two windows were established at both nasal bones, located about $20 \mathrm{~mm}$ anterior to the nasofrontal suture line and $5 \mathrm{~mm}$ from the middle suture line. The sinus mucosa was elevated with a blunt-ended curette to avoid membrane perforation and anteroventrally to accommodate the bone graft. In the control group, approximately $0.25 \mathrm{~mL}$ of anorganic bovine grafting material (Bio-Oss; Geistlich Pharma, Wolhusen, Switzerland) was grafted in the new compartment under the elevated sinus membrane, and the bony window was replaced after careful elevation of the sinus mucosa. In the experimental group, $0.25 \mathrm{~mL}$ of demineralized particulate human tooth bone was grafted in the new compartment under the elevated sinus membrane, and the bony window was repositioned over the bone graft.(Fig. 1) The flap was sutured with a 4-0 nylon suture (Blue nylon; Ailee, Busan, Korea). All animals were administered antibiotics intramuscularly, with $20 \mathrm{mg} / \mathrm{kg}$ of gentamycin (Donghwa, Seoul, Korea) given for three days postoperatively.

\section{Tissue preparation}

The rabbits were sacrificed at two and eight weeks under general anesthesia after all intramuscular injections of urethane (Junsei Chemical, Tokyo, Japan). The augmented sinus was segmented with a micro-saw from the cranium and fixed with neutral-buffered formalin for 24 hours, washed with 0.1 $\mathrm{M}$ of PBS, and demineralized with $10 \%$ formic acid for 10 days. The specimen was embedded in paraffin (Paraplast; Sigma-Aldrich, St. Louis, MO, USA) and sliced coronally into serial sections measuring $5 \mu \mathrm{m}$ thick. Both augmented
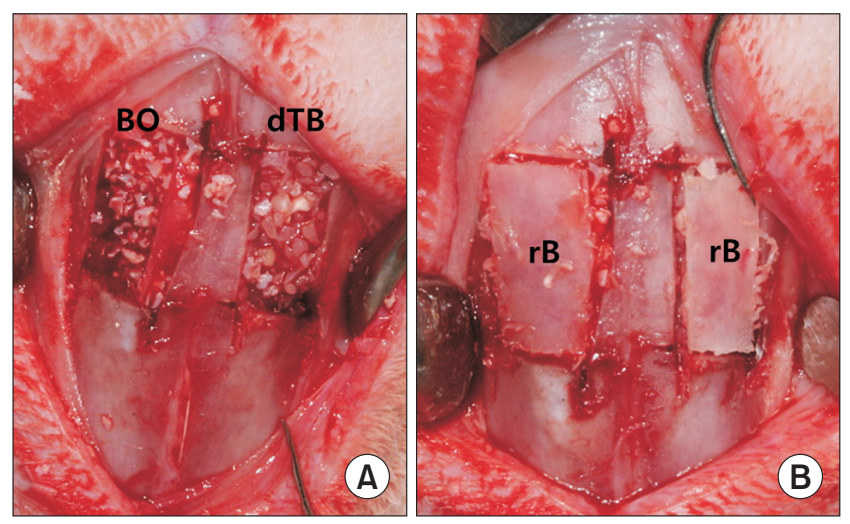

Fig. 1. In the control group, Bio-Oss material was grafted into the new compartments established under the elevated sinus membrane on the left side. In the experimental group, demineralized particulate human tooth bone was grafted into the same area on the right side $(A)$. In both groups, the replaceable bony window was replaced over the bone graft (B). (BO: Bio-Oss, dTB: demineralized particulate human tooth bone, $\mathrm{rB}$ : replaceable bone) Dong-Seok Sohn et al: Comparison of immunohistochemical analysis on sinus augmentation using demineralized tooth graft and bovine bone. J Korean Assoc Oral Maxillofac Surg 2021 
sinuses were included in the specimen for comparison. The specimens were stained with $\mathrm{H} \& \mathrm{E}$ and examined under light microscopy for newly formed bone and soft tissue changes in the new compartment of the maxillary sinus.

\section{Bromodeoxyuridine (BrdU) Immunohistochemistry}

Serial sections in the control and experimental groups were stained immunohistochemically for markers of proliferating osteoprogenitor cells using BrdU (Sigma-Aldrich). To accomplish BrdU staining, operated rabbits were given $25 \mathrm{mg} /$ $\mathrm{kg}$ of BrdU intraperitoneally. At 24 hours after administration of BrdU, the rabbits were sacrificed, and paraffin-embedded sections were created. These sections were incubated in $0.1 \%$ trypsin for 10 minutes at $37^{\circ} \mathrm{C}$ and $1 \mathrm{~N}$ of $\mathrm{HCl}$ for $30 \mathrm{~min}-$ utes at $56^{\circ} \mathrm{C}$ to denature the DNA. Endogenous peroxidases were inhibited by preincubation in $0.3 \% \mathrm{H}_{2} \mathrm{O}_{2}$ in PBS for 30 minutes, and nonspecific protein binding was blocked in PBS containing 10\% normal horse serum (Vector Laboratories, Burlingame, CA, USA) for 30 minutes. The sections were incubated in monoclonal anti-BrdU (1:100; Sigma-Aldrich) for two hours at room temperature and washed three times with PBS. The secondary antibody (1:100), biotinylated anti-mouse immunoglobulin G (Vector Laboratories), was deposited for one hour at room temperature on the sections, which were washed three times with PBS. Next, avidin-biotin-peroxidase complex (Vector Laboratories) was placed on the sections for one hour and washed off by three rinses with PBS; this was followed by a peroxidase reaction using 0.05 $\mathrm{M}$ of Tris- $\mathrm{HCl}\left(\mathrm{pH}\right.$ 7.6) containing $0.01 \% \mathrm{H}_{2} \mathrm{O}_{2}$ and $0.05 \%$ 3,3'-diaminobenzidine (Sigma-Aldrich). The sections were counterstained with hematoxylin and mounted. The slides were examined using the Axiophot photomicroscope (Carl Zeiss, Jena, Germany) and AxioCam MRc5 camera (Carl Zeiss). Each slide was evaluated for frequency of immunopositive cells or nuclei.

\section{Number of BrdU-labeled cells}

The number of BrdU-positive nuclei or cells was counted. Ten randomly selected fields from each group were photographed, and the AxioVision SE64 (Carl Zeiss) program was used for analysis. The BrdU-labeled cells were counted in soft tissues, including fibrous tissue, vascular tissue, and bone marrow of the augmented sinus, and calculated per 1 $\mathrm{mm}^{2}$ of soft tissue of the augmented sinus. Statistical analyses were performed with the IBM SPSS Statistics program for Windows (ver. 19.0; IBM, Armonk, NY, USA). In addition to standard descriptive statistical calculations (means and standard deviations), ANOVA was used to determine intraand intergroup statistical differences. When ANOVA yielded significant results, indicating that the group was significantly different from the others, Tukey's test was performed. Mean values are accompanied by $95 \%$ confidence intervals, and all data are expressed as mean \pm standard deviation. Statistical significance was noted at $P<0.05$.

\section{Immunohistochemical assay}

Immunohistochemical studies were performed using mouse anti-PCNA monoclonal antibody (PC10; Santa Cruz Biotechnology, Dallas, TX, USA), mouse anti-collagen I monoclonal antibody (COL-1; Abcam, Cambridge, UK), mouse antiosteopontin monoclonal antibody (53; Abcam), and mouse
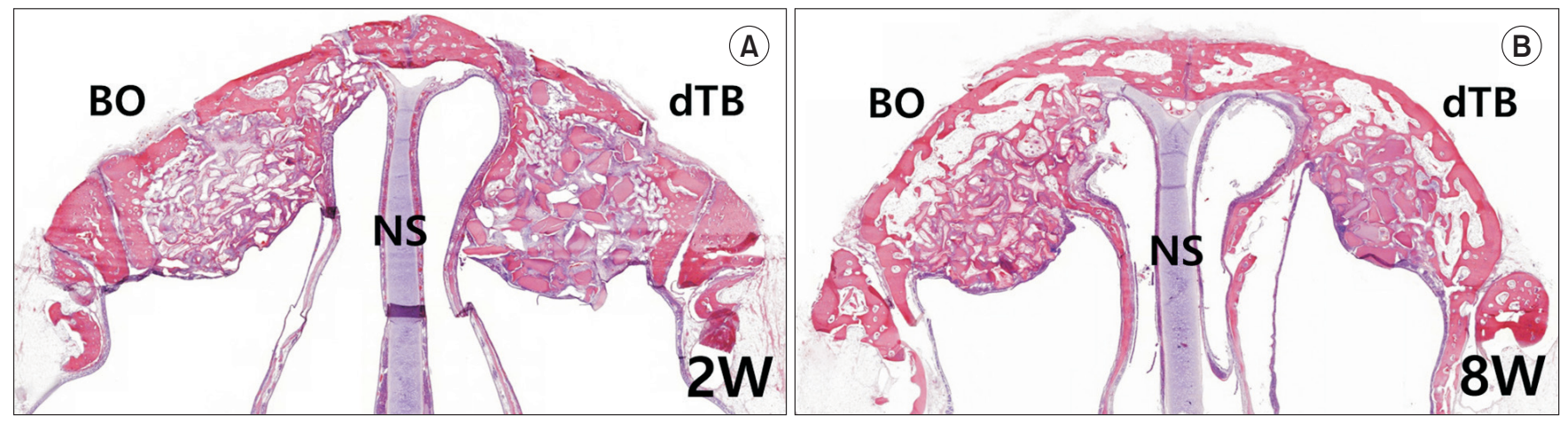

Fig. 2. Coronal sections of a rabbit nasal cavity stained with $H \& E(\times 12.5)$ at two weeks (2W) (A) and eight weeks (8W) (B) after surgery. In each image, the left side shows the grafted sinus treated with Bio-Oss material after maxillary sinus membrane elevation with replacement of the bony window, while the right side shows the grafted sinus treated with demineralized particulate human tooth bone with replacement of the bony window. (BO: Bio-Oss, dTB: demineralized particulate human tooth bone, NS: nasal septum)

Dong-Seok Sohn et al: Comparison of immunohistochemical analysis on sinus augmentation using demineralized tooth graft and bovine bone. J Korean Assoc Oral Maxillofac Surg 2021 
anti-osteocalcin monoclonal antibody (OCG3; Abcam). The paraffin-embedded sections were cleared, dehydrated, and washed with PBS. Endogenous peroxidases were inhibited by preincubation in $0.3 \% \mathrm{H}_{2} \mathrm{O}_{2}$ in PBS for 30 minutes, and nonspecific protein binding was blocked in PBS containing $10 \%$ normal horse serum (Vector Laboratories) for 30 minutes. The sections were incubated in primary antibodies (1:50$1: 200)$ for two hours at room temperature and washed three times with PBS. The secondary antibody (1:100), biotinylated anti-mouse immunoglobulin $\mathrm{G}$, was placed on the sections for one hour at room temperature and washed off by three rinses with PBS. Then, avidin-biotin-peroxidase complex was placed on the sections for one hour and washed off three times with PBS. A peroxidase reaction using $0.05 \mathrm{M}$ of Tris$\mathrm{HCl}\left(\mathrm{pH}\right.$ 7.6) containing $0.01 \% \mathrm{H}_{2} \mathrm{O}_{2}$ and $0.05 \%$ 3,3'-diaminobenzidine was provoked. The sections were counterstained with hematoxylin and mounted; slides were examined using the Axiophot photomicroscope and AxioCam MRc5 camera. All the experiment was performed from July 2016 to April 2017.

\section{Results}

\section{Histological analysis}

No signs of inflammation were observed in the control or experimental group by H\&E staining under a light mi- croscope; moreover, the Bio-Oss material and demineralized particulate human tooth bone were lightly stained and well-differentiated from surrounding tissue.(Fig. 2) In the control group, two weeks after surgery, newly formed bone was revealed on the surface of the Bio-Oss material.(Fig. 2. A) Eight weeks after surgery, the newly formed bone appeared thicker and contained many osteocytes. A significant amount of mature lamellar bone was observed inside the newly formed bone, and a portion of bone marrow containing adipose tissue was observed on the floor of the replaceable bone.(Fig. 2. B) In the experimental group, two weeks after surgery, newly formed bone was revealed on the surface of the demineralized particulate human tooth bone.(Fig. 2. A) Six weeks later, the thickness and the density of the new bone were increased. A significant amount of mature lamellar bone was revealed inside the newly formed bone, and a portion of bone marrow containing adipose tissue was observed on the floor of both the replaceable bone and nasal bone. The size and density of the demineralized particulate human tooth bone decreased relative to those at two weeks after surgery. (Fig. 2. B)

\section{BrdU immunohistochemistry}

In the control group, two weeks after surgery, many BrdUpositive cells were observed on the surface of the Bio-Oss material and in the connective tissue.(Fig. 3. A) Also, some

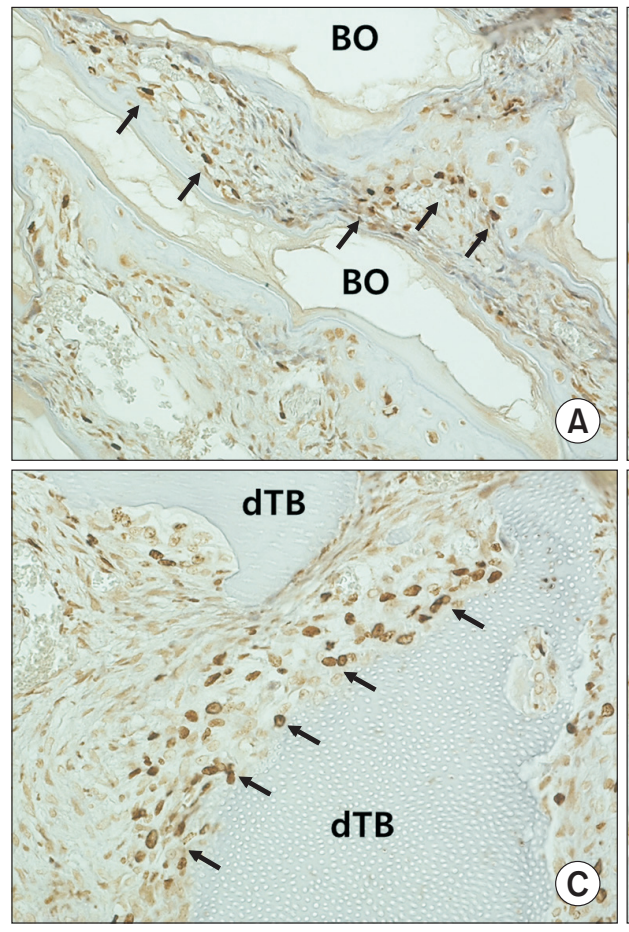

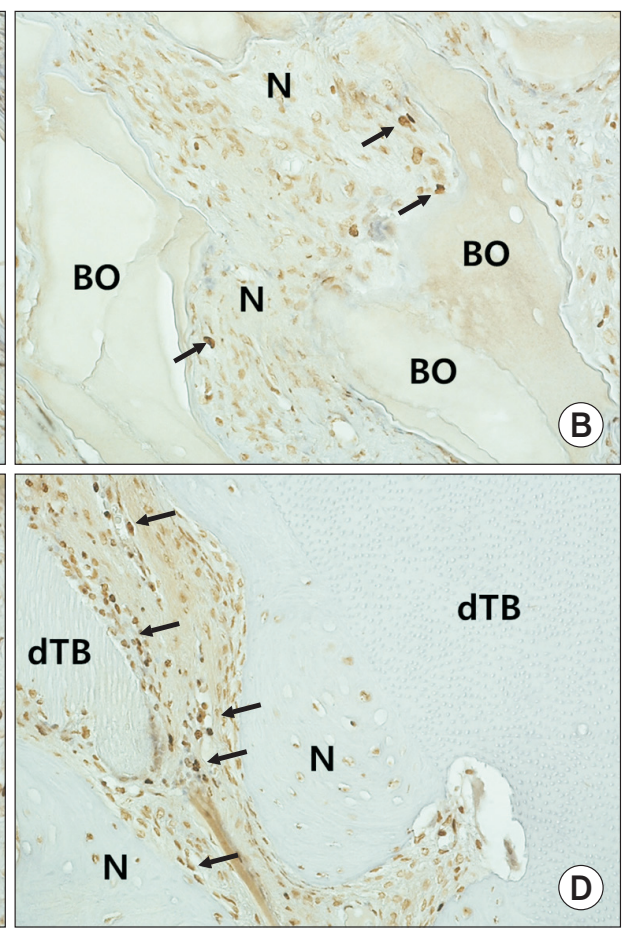

(B).

(D)
Fig. 3. Immunohistochemical staining (×200) for bromodeoxyuridine (BrdU) in the control group at two weeks (A) and eight weeks (B) and the experimental group at two weeks (C) and eight weeks (D). BrdU-positive cells (arrows) confirmed the existence of osteoblasts on the surface of newly formed bone and graft materials. (BO: Bio-Oss, N: newly formed bone, dTB: demineralized particulate human tooth bone) Dong-Seok Sohn et al: Comparison of immunohistochemical analysis on sinus augmentation using demineralized tooth graft and bovine bone. J Korean Assoc Oral Maxillofac Surg 2021 
cells strongly positive for BrdU were observed among the osteoblasts on the surface of the newly formed bone and among the osteoprogenitor cells in the surrounding connective tissue. Eight weeks after surgery, a much weaker expression of cells positive for BrdU was observed.(Fig. 3. B) In the experimental group, two weeks after surgery, many BrdU-positive cells were observed on the surface of the demineralized particulate human tooth bone and the newly formed bone as well as in

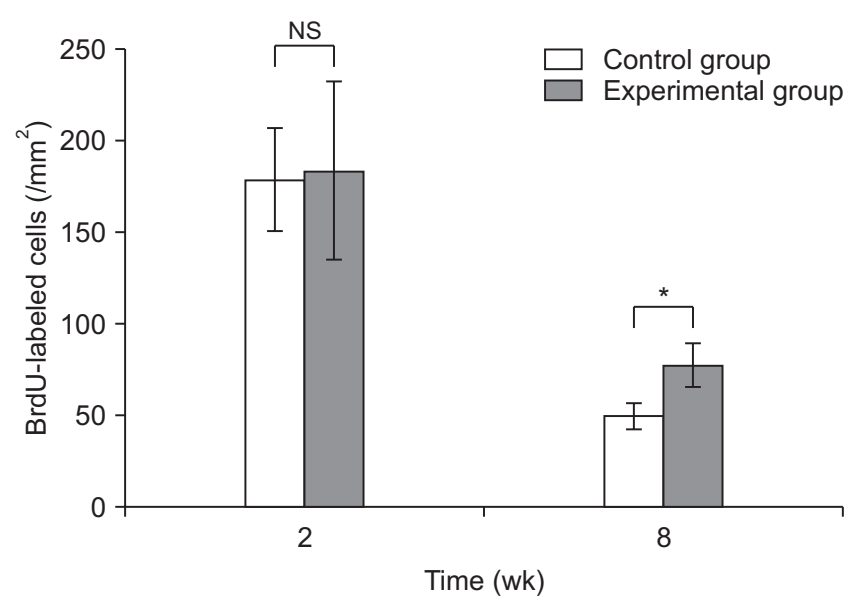

Fig. 4. Histomorphometric measurements of the number of bromodeoxyuridine (BrdU)-labeled cells per $1 \mathrm{~mm}^{2}$ of soft tissue of the augmented sinus. The soft tissue area contains fibrous tissue, vascular tissue, and bone marrow of the augmented sinus $\left({ }^{\star} P<0.05\right)$. (NS: not significant)

Dong-Seok Sohn et al: Comparison of immunohistochemical analysis on sinus augmentation using demineralized tooth graft and bovine bone. J Korean Assoc Oral Maxillofac Surg 2021 the connective tissue.(Fig. 3. C) Strong expression for BrdU was observed in the osteoblasts on the surface of the demineralized particulate human tooth bone. Some cells strongly positive for BrdU were observed among the osteoprogenitor cells in the surrounding connective tissue. Eight weeks after surgery, cells positive for BrdU showed moderate expression in osteoblasts on the surface of the demineralized particulate human tooth bone and the newly formed bone.(Fig. 3. D)

\section{Number of BrdU-labeled cells}

In the control group, numbers of BrdU-labeled cells per 1 $\mathrm{mm}^{2}$ of soft tissue of the augmented sinus at two and eight weeks totaled $178.26 \pm 27.96$ and $49.52 \pm 7.03$, respectively. One-way ANOVA and post-hoc comparisons showed that the number of BrdU-labeled cells at eight weeks was significantly less than that at two weeks, with $P<0.05$.(Fig. 4) In the experimental group, the numbers of BrdU-labeled cells per $1 \mathrm{~mm}^{2}$ of soft tissue of the augmented sinus at two and eight weeks totaled $183.07 \pm 48.18$ and $77.24 \pm 11.67$, respectively, with the number of BrdU-labeled cells at eight weeks being significantly less than that at two weeks, with $P<0.05$.(Fig. 4) Notably, the number of BrdU-labeled cells at two weeks in the control group was not significantly different from that at two weeks in the experimental group, but the number of BrdU-labeled cells at eight weeks in the control group was significantly less than that at eight weeks in the experimental

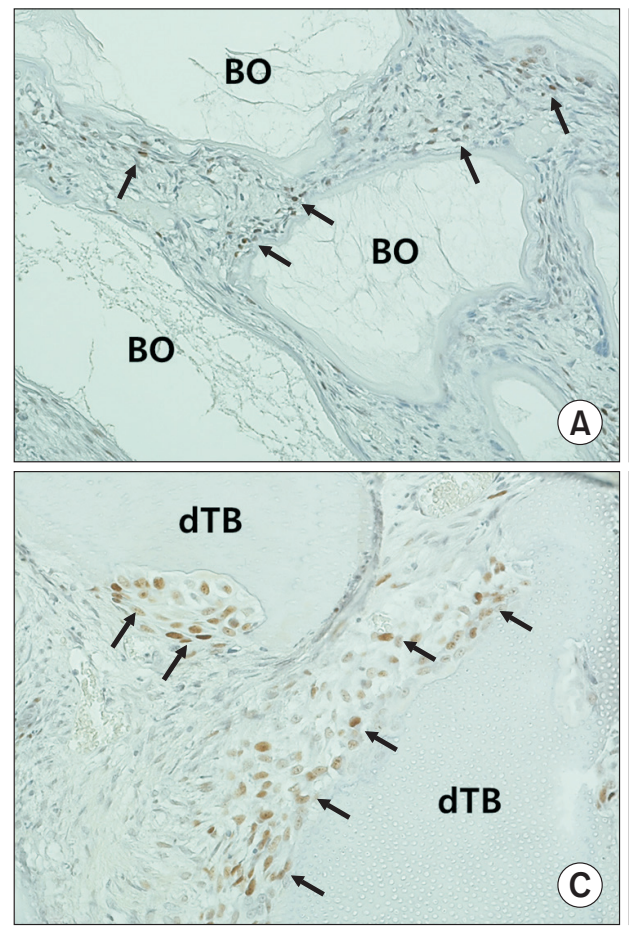

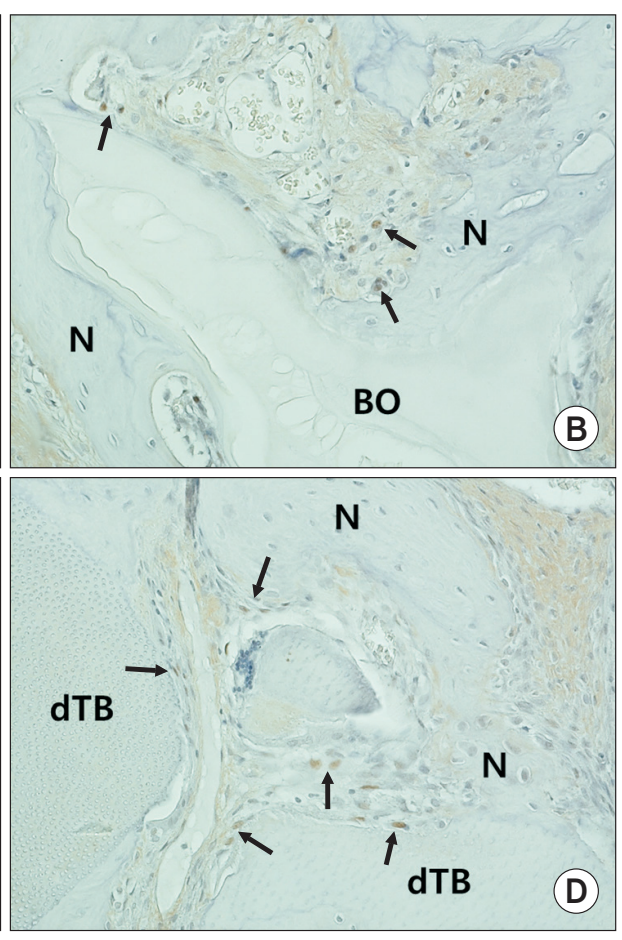

Fig. 5. Immunohistochemical staining $(\times 200)$ with proliferating-cell nuclear antigen (PCNA) in the control group at two weeks (A) and eight weeks (B) and the experimental group at two weeks (C) and eight weeks (D). Arrows indicate PCNA-positive cells. (BO: Bio-Oss, N: newly formed bone, dTB: demineralized particulate human tooth bone) Dong-Seok Sohn et al: Comparison of immunohistochemical analysis on sinus augmentation using demineralized tooth graft and bovine bone. J Korean Assoc Oral Maxillofac Surg 2021 
group, with $P<0.05$.(Fig. 4)

\section{Expression of PCNA}

In the control group, two weeks after surgery, many PCNA-positive cells were observed on the surface of the BioOss material and in the connective tissue.(Fig. 5. A) Eight weeks after surgery, the expression of PCNA was reduced and some PCNA-positive cells were observed on the surface of the newly formed bone.(Fig. 5. B) In the experimental group, two weeks after surgery, PCNA-positive cells were observed in high numbers on the surface of the demineralized particulate human tooth bone and newly formed bone (Fig. 5. C), and some PCNA-positive cells were observed in the
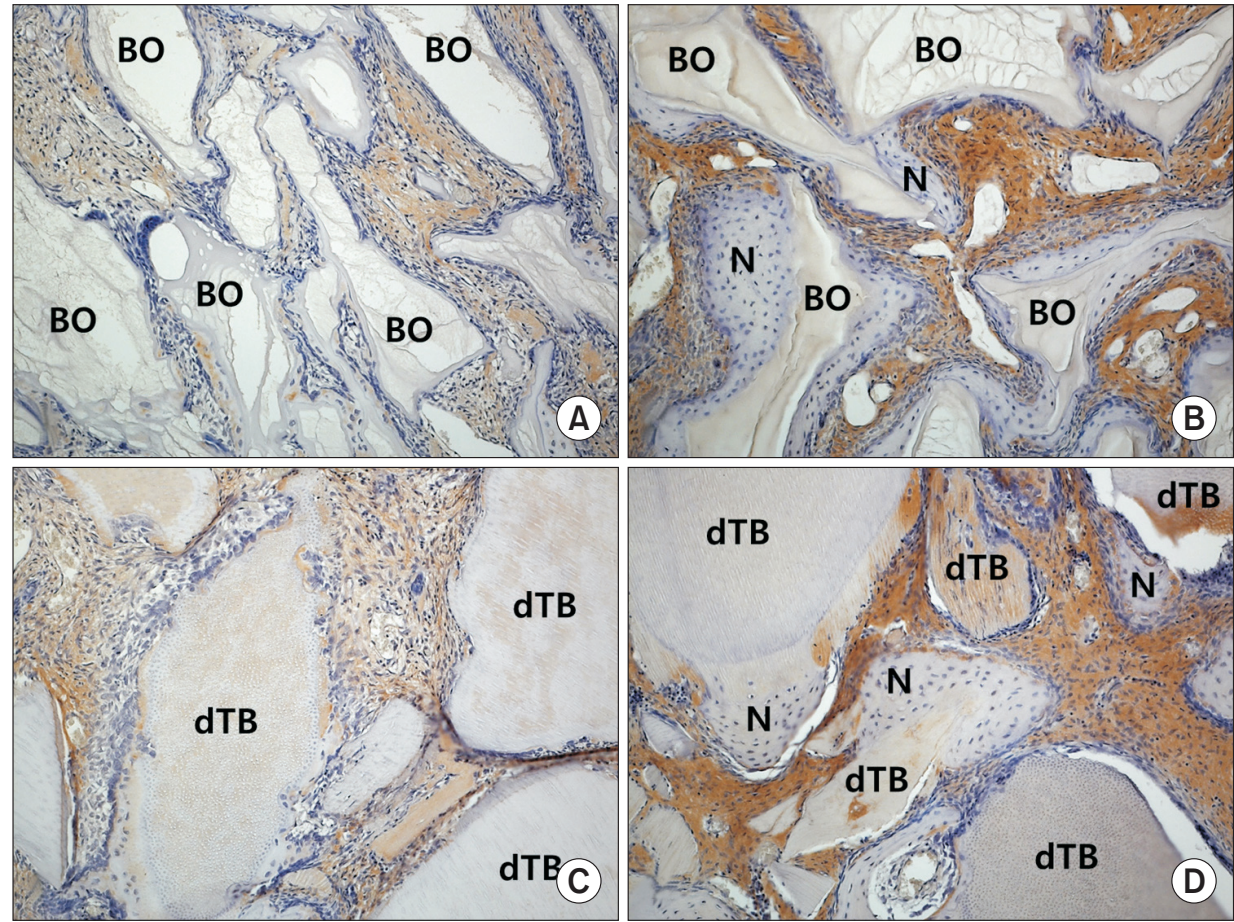

(B)

Fig. 6. Immunohistochemical staining $(\times 100)$ for type I collagen in the control group at two weeks (A) and eight weeks (B) and the experimental group at two weeks (C) and eight weeks (D). (BO: Bio-Oss, N: newly formed bone, dTB: demineralized particulate human tooth bone)

Dong-Seok Sohn et al: Comparison of immunohistochemical analysis on sinus augmentation using demineralized tooth graft and bovine bone. J Korean Assoc Oral Maxillofac Surg 2021
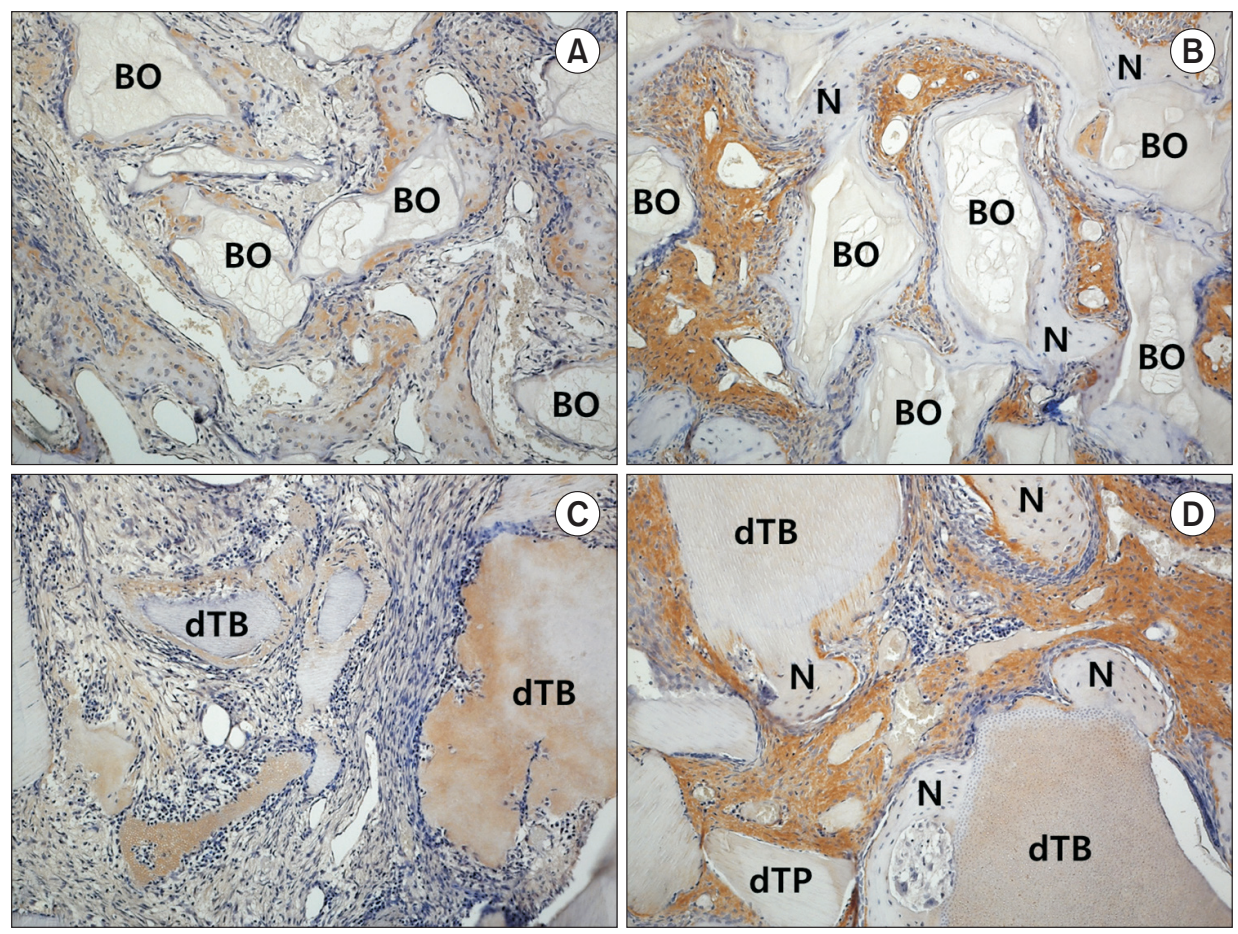

Fig. 7. Immunohistochemical staining $(\times 100)$ for osteopontin in the control group at two weeks (A) and eight weeks (B) and the experimental group at two weeks (C) and eight weeks (D). (BO: Bio-Oss, N: newly formed bone, dTB: demineralized particulate human tooth bone)

Dong-Seok Sohn et al: Comparison of immunohistochemical analysis on sinus augmentation using demineralized tooth graft and bovine bone. J Korean Assoc Oral Maxillofac Surg 2021 
soft tissue. Strong expression of PCNA was recorded among osteoblasts on the surface of the demineralized particulate human tooth bone. Eight weeks after surgery, the expression of PCNA was slightly decreased and PCNA-positive cells were observed on the surface of the demineralized particulate human tooth bone.(Fig. 5. D) Overall, the immunoreactivity of PCNA at eight weeks was slightly higher in the experimental group than in the control group.

\section{Expression of type I collagen}

In the control group, two weeks after surgery, weak expression of type I collagen was observed on the surface of the Bio-Oss material and in surrounding connective tissue.(Fig. 6. A) Eight weeks after surgery, strong expression of type I collagen was confirmed on the surface of the newly formed bone and Bio-Oss material and among osteoblasts.(Fig. 6. B) In the experimental group, two weeks after surgery, weak expression of type I collagen was observed on the surface of the demineralized particulate human tooth bone and in surrounding connective tissue.(Fig. 6. C) Finally, eight weeks after surgery, strong expression of type I collagen was observed on the surface of the newly formed bone and demineralized particulate human tooth bone and in fibroblast-rich dense connective tissue.(Fig. 6. D)

\section{Expression of osteopontin}

In the control group, two weeks after surgery, slight positive expression of osteopontin was observed on the surface of the Bio-Oss material and in surrounding connective tissue. (Fig. 7. A) Eight weeks after surgery, strong expression of osteopontin was present in surrounding connective tissue and on the surface of the newly formed bone and the Bio-Oss material.(Fig. 7. B) Meanwhile, in the experimental group, two weeks after surgery, weak expression of osteopontin was observed on the surface of the demineralized particulate human tooth bone and in surrounding connective tissue (Fig. 7. C), while, at eight weeks, strong expression of type I collagen was observed on the surface of the newly formed bone and demineralized particulate human tooth bone and in fibroblastrich dense connective tissue.

\section{Expression of osteocalcin}

In the control group, two weeks after surgery, weak expression of osteocalcin was observed on the surface of the BioOss material and in surrounding connective tissue (Fig. 8. A), while, eight weeks after surgery, a modulating expression level of osteocalcin was present in surrounding connective tissue. Some osteocalcin-positive osteocytes were observed in the newly formed bone.(Fig. 8. B) In the experimental group, two weeks after surgery, slight positive expression of
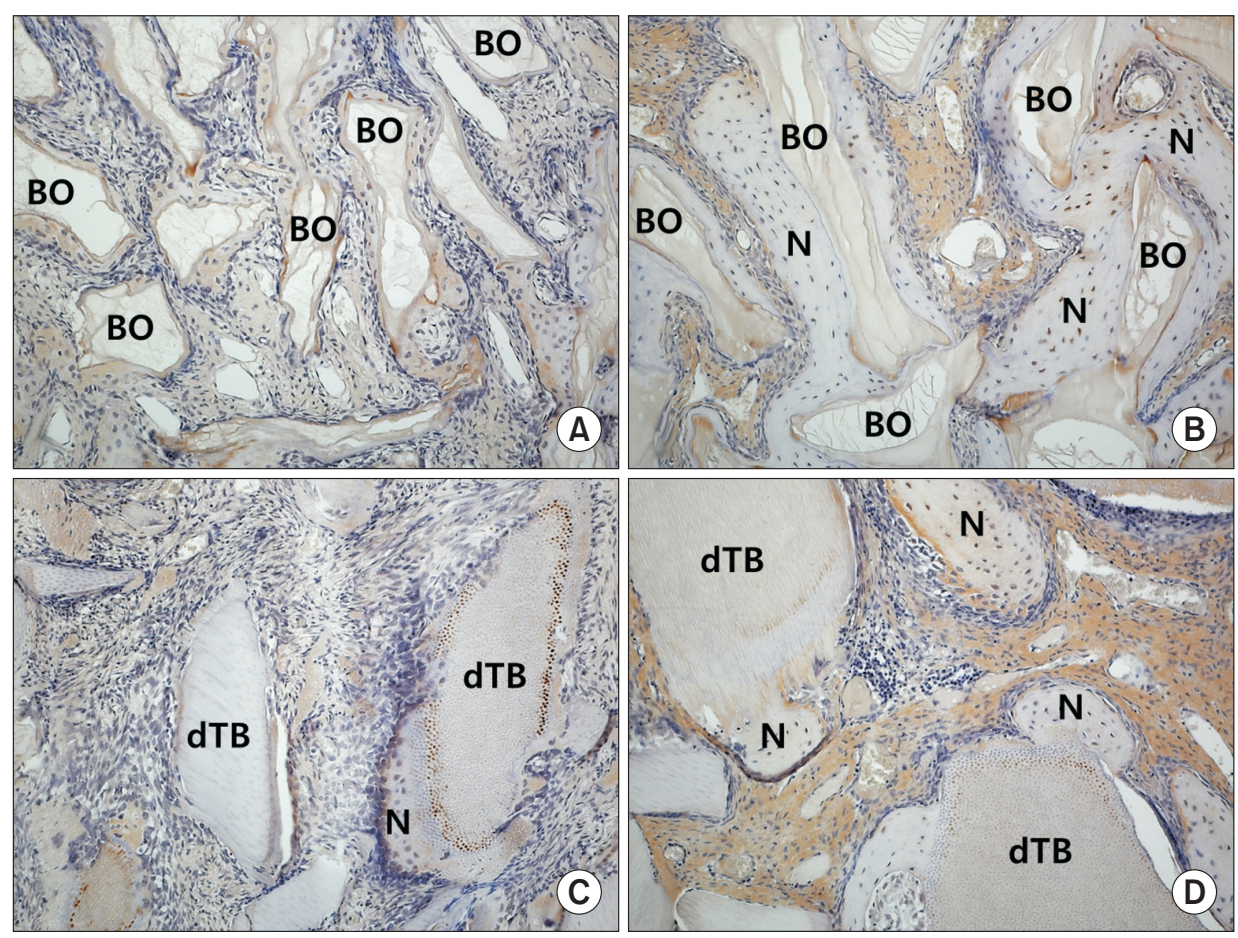

Fig. 8. Immunohistochemical staining $(\times 100)$ for osteocalcin in the control group at two weeks (A) and eight weeks (B) and the experimental group at two weeks (C) and eight weeks (D). (BO: Bio-Oss, N: newly formed bone, dTB: demineralized particulate human tooth bone)

Dong-Seok Sohn et al: Comparison of immunohistochemical analysis on sinus augmentation using demineralized tooth graft and bovine bone. J Korean Assoc Oral Maxillofac Surg 2021 
osteocalcin was observed on the surface of the demineralized particulate human tooth bone and in surrounding connective tissue (Fig. 8. C), and some degree of positive expression of osteocalcin was found in the matrix of the demineralized particulate human tooth bone. Eight weeks after surgery, a modulating expression of osteocalcin was observed on the surface of the newly formed bone and demineralized particulate human tooth bone and in fibroblast-rich dense connective tissue. Also, a strong expression level of osteocalcin was observed on the surface of newly formed bone and demineralized particulate human tooth bone and in fibroblast-rich dense connective tissue.(Fig. 8. D)

\section{Discussion}

As an alternative bone graft to osteoinductive autologous bone, dTB is adopted widely for reconstruction of bony defects associated with implant-supported reconstruction and/ or that develop following removal of bony lesions ${ }^{16-18}$. Osteoinductive and osteoconductive capabilities in both block and particulate types of demineralized tooth bone have been confirmed by histomorphometric analysis ${ }^{19,20}$. According to a recently published histomorphometric comparative study employing demineralized tooth bone and anorganic bovine bone, demineralized tooth bone demonstrated a significantly greater potential for bone reformation than did osteoconductive bovine bone in the maxillary sinus. In addition, bone remodeling, which is considered a component of successful bone grafting, was observed inside and along the surface of demineralized particulate human tooth bone, unlike Bio-Oss material, in this histomorphometric study ${ }^{20}$. Histomorphometric analysis is used to evaluate quantitative measurements of bone reformation.

Meanwhile, immunohistochemical analysis employing antigens (bone markers) is applied commonly to evaluate the distribution and localization of differentially expressed proteins and immunoreactivity in research ${ }^{21}$. In the present study, in addition to the histomorphometric analysis of previous results, we conducted an immunohistochemical analysis.

Proliferating cells in tissue can be identified by immunohistochemical detection of BrdU or PCNA. BrdU is a thymidine analog that can be integrated into cells undergoing DNA synthesis. BrdU immunohistochemistry facilitates in vivo detection of cells in the $\mathrm{S}$ phase of mitosis ${ }^{22}$. Pulse labeling of DNA with BrdU has been used to identify adult stem cells in a variety of tissues throughout the body. BrdU labeling determines the identities of newly born cells as well as proliferat- ing and differentiating cells ${ }^{23,24}$.

PCNA is a $36-\mathrm{kDa}$ nucleus protein whose expression increases in the late G1 phase and continues through most of the S phase of the cell cycle ${ }^{25}$. Because PCNA acts as a processing factor for DNA polymerase during DNA replication, PCNA has applications as a marker for DNA synthesis in cell proliferation $^{26}$.

The difference between BrdU and PCNA is that BrdU is an extrinsic marker of cell proliferation, whereas PCNA is an intrinsic marker of cell proliferation. BrdU can be administered at different times to study cell proliferation and differentiation. The advantage of the BrdU method is that it is more suitable for the analysis of several treatment groups with sufficient numbers to achieve statistical significance ${ }^{27}$.

In this study, a large number of BrdU-labeled cells was observed at two weeks, with no significant difference between the control and experimental groups. However, the number of BrdU-labeled cells at eight weeks in the control group was significantly less than that at eight weeks in the experimental group. Also, the expression of PCNA was slightly higher in the experimental group than in the control group at eight weeks. These results suggest that demineralized human tooth bone is more beneficial for long-term osteoinduction than is osteoconductive Bio-Oss material.

Type I collagen, osteopontin, and osteocalcin were used as markers in the present study to discern the area and intensity of new bone formation in the maxillary sinus. Type I collagen is a collagenous protein-forming bone matrix that is very abundant in bone, skin, and tendons. Type I collagen is synthesized by osteoblasts and formed of bony tissue with minerals during the process of intramembranous ossification ${ }^{28}$. Osteopontin is a highly phosphorylated sialoprotein that is a prominent component of the mineralized extracellular matrix of bone ${ }^{29}$. In bone, osteopontin is produced by differentiated osteoblasts and osteocytes as well as by osteoclasts. It appears to be an important component in communication between these cells, and there is strong evidence supporting the involvement of osteopontin in the formation, migration, and attachment of osteoclasts and their resorptive activity ${ }^{30}$. Osteocalcin, which regulates both bone resorption and new bone mineralization, is a very abundant, noncollagenous protein synthesized by mature osteoblasts. Also, osteocalcin mediates osteoclast adhesion to new bone and regulates calcium metabolism; this means that it is a good marker for osteogenic maturation $^{31,32}$. Type I collagen, osteopontin, and osteocalcin have characteristics that are often associated with osteoblastic differentiation. Type I collagen appears in the early stages 
of osteogenic maturation, while osteopontin appears in the middle stages and osteocalcin appears in the late stages. Because the expression of bone matrix proteins depends on the maturation of each osteoblast, it follows that the maturation of osteoblasts can be determined to some extent by the expression levels of bone matrix proteins ${ }^{33}$.

In this study, the expression levels of type I collagen, osteopontin, and osteocalcin were significantly increased at eight weeks relative to at two weeks in both groups. These results suggest that both demineralized human tooth bone and Bio-Oss material exhibit similar osteogenesis and osteoconduction capabilities in the rabbit maxillary sinus. To our knowledge, this is the first comparative immunohistochemical analysis to show that demineralized particulate tooth bone exhibits more active bone regeneration in comparison with anorganic bovine bone. Therefore, demineralized particulate tooth bone, as an autologous biomaterial, might be used as a bone graft material for reconstruction of bony defects in implant dentistry and oral and maxillofacial surgery.

\section{Conclusion}

According to the present study, using immunohistochemical analysis, we concluded that (1) greater osteoinduction was revealed in the experimental group treated using demineralized human tooth bone than in the control group treated using Bio-Oss material and (2) active expression of bone reformation in the rabbit maxillary sinus was present in both the control and experimental groups.

\section{ORCID}

Dong-Seok Sohn, https://orcid.org/0000-0001-9955-0974

Ji-Rak Kim, https://orcid.org/0000-0002-1326-3948

Hyung-Gyun Kim, https://orcid.org/0000-0002-3384-5275

Hyun-Suk Choi, https://orcid.org/0000-0002-0381-3870

Yong-Suk Moon, https://orcid.org/0000-0001-5405-8919

\section{Authors' Contributions}

D.S.S. participated in the study design and performed the experiment. J.R.K. participated in the coordination and helped to draft the manuscript. H.G.K. performed the experiment and data collection. H.S.C. participated in the coordination and helped to draft the manuscript. Y.S.M. participated in the study design interpretation of data. All authors read and approved the final manuscript.

\section{Ethics Approval and Consent to Participate}

This study was approved by the Animal Care and Use Committee at the Catholic University Medical Center of Daegu (DCIAFCR-160705-3-Y).

\section{Conflict of Interest}

No potential conflict of interest relevant to this article was reported.

\section{References}

1. Misch CE. Maxillary sinus augmentation for endosteal implants: organized alternative treatment plans. Int J Oral Implantol 1987:4:49-58.

2. Aghaloo TL, Moy PK. Which hard tissue augmentation techniques are the most successful in furnishing bony support for implant placement? Int J Oral Maxillofac Implants 2007;22 Suppl:49-70.

3. Duan DH, Fu JH, Qi W, Du Y, Pan J, Wang HL. Graft-free maxillary sinus floor elevation: a systematic review and metaanalysis. J Periodontol 2017;88:550-64. https://doi.org/10.1902/ jop.2017.160665

4. Kent JN, Block MS. Simultaneous maxillary sinus floor bone grafting and placement of hydroxylapatite-coated implants. J Oral Maxillofac Surg 1989;47:238-42. https://doi.org/10.1016/02782391(89)90225-5

5. Wagner JR. A 3 1/2-year clinical evaluation of resorbable hydroxylapatite OsteoGen (HA Resorb) used for sinus lift augmentations in conjunction with the insertion of endosseous implants. J Oral Implantol 1991;17:152-64.

6. Cordioli G, Mazzocco C, Schepers E, Brugnolo E, Majzoub Z. Maxillary sinus floor augmentation using bioactive glass granules and autogenous bone with simultaneous implant placement. Clinical and histological findings. Clin Oral Implants Res 2001;12:2708. https://doi.org/10.1034/j.1600-0501.2001.012003270.x

7. Moon JW, Sohn DS, Heo JU, Kim JS. Comparison of two kinds of bovine bone in maxillary sinus augmentation: a histomorphometric study. Implant Dent 2015;24:19-24. https://doi.org/10.1097/ ID.0000000000000187

8. Lee KH, Kim YK, Cho WJ, Um IW, Murata M, Mitsugi M. Autogenous tooth bone graft block for sinus augmentation with simultaneous implant installation: a technical note. J Korean Assoc Oral Maxillofac Surg 2015;41:284-9. https://doi.org/10.5125/jkaoms.2015.41.5.284

9. Boyne PJ, James RA. Grafting of the maxillary sinus floor with autogenous marrow and bone. J Oral Surg 1980;38:613-6.

10. van den Bergh JP, ten Bruggenkate CM, Krekeler G, Tuinzing DB. Sinusfloor elevation and grafting with autogenous iliac crest bone. Clin Oral Implants Res 1998;9:429-35. https://doi.org/10.1034/ j.1600-0501.1996.090608.x

11. Yeomans JD, Urist MR. Bone induction by decalcified dentine implanted into oral, osseous and muscle tissues. Arch Oral Biol 1967;12:999-1008. https://doi.org/10.1016/0003-9969(67)90095-7

12. Bessho K, Tagawa T, Murata M. Purification of rabbit bone morphogenetic protein derived from bone, dentin, and wound tissue after tooth extraction. J Oral Maxillofac Surg 1990;48:162-9. https:// doi.org/10.1016/s0278-2391(10)80204-6

13. Jun SH, Ahn JS, Lee JI, Ahn KJ, Yun PY, Kim YK. A prospective study on the effectiveness of newly developed autogenous tooth bone graft material for sinus bone graft procedure. J Adv Prosthodont 2014;6:528-38. https://doi.org/10.4047/jap.2014.6.6.528 
14. Kim YK, Lee J, Yun JY, Yun PY, Um IW. Comparison of autogenous tooth bone graft and synthetic bone graft materials used for bone resorption around implants after crestal approach sinus lifting: a retrospective study. J Periodontal Implant Sci 2014;44:21621. https://doi.org/10.5051/jpis.2014.44.5.216

15. Kim ES. Autogenous fresh demineralized tooth graft prepared at chairside for dental implant. Maxillofac Plast Reconstr Surg 2015;37:8. https://doi.org/10.1186/s40902-015-0009-1

16. Kim YK, Lee JH, Um IW, Cho WJ. Guided bone regeneration using demineralized dentin matrix: long-term follow-up. J Oral Maxillofac Surg 2016;74:515.e1-9. https://doi.org/10.1016/ j.joms.2015.10.030

17. Kim ES, Kang JY, Kim JJ, Kim KW, Lee EY. Space maintenance in autogenous fresh demineralized tooth blocks with platelet-rich plasma for maxillary sinus bone formation: a prospective study. Springerplus 2016;5:274. https://doi.org/10.1186/s40064-0161886-1

18. Lee J, Lee EY, Park EJ, Kim ES. An alternative treatment option for a bony defect from large odontoma using recycled demineralization at chairside. J Korean Assoc Oral Maxillofac Surg 2015;41:109-15. https://doi.org/10.5125/jkaoms.2015.41.2.109

19. Kabir MA, Murata M, Akazawa T, Kusano K, Yamada K, Ito M. Evaluation of perforated demineralized dentin scaffold on bone regeneration in critical-size sheep iliac defects. Clin Oral Implants Res 2017;28:e227-35. https://doi.org/10.1111/clr.13000

20. Xu X, Sohn DS, Kim HG, Lee SJ, Moon YS. Comparative histomorphometric analysis of maxillary sinus augmentation with deproteinized bovine bone and demineralized particulate human tooth graft: an experimental study in rabbits. Implant Dent 2018;27:32431. https://doi.org/10.1097/ID.0000000000000755

21. Ramos-Vara JA, Miller MA. When tissue antigens and antibodies get along: revisiting the technical aspects of immunohistochemistry--the red, brown, and blue technique. Vet Pathol 2014;51:42-87. https://doi.org/10.1177/0300985813505879

22. Dolbeare F. Bromodeoxyuridine: a diagnostic tool in biology and medicine, part I: historical perspectives, histochemical methods and cell kinetics. Histochem J 1995;27:339-69.

23. Okafuji N, Liu ZJ, King GJ. Assessment of cell proliferation during mandibular distraction osteogenesis in the maturing rat. Am J Orthod Dentofacial Orthop 2006;130:612-21. https://doi.org/10.1016/ j.ajodo.2005.06.023

24. Shimada A, Shibata T, Komatsu K, Nifuji A. Improved methods for immunohistochemical detection of $\mathrm{BrdU}$ in hard tissue. J Immunol Methods 2008;339:11-6. https://doi.org/10.1016/j.jim.2008.07.013

25. Prelich G, Tan CK, Kostura M, Mathews MB, So AG, Downey $\mathrm{KM}$, et al. Functional identity of proliferating cell nuclear an- tigen and a DNA polymerase-delta auxiliary protein. Nature 1987;326:517-20. https://doi.org/10.1038/326517a0

26. Garcia RL, Coltrera MD, Gown AM. Analysis of proliferative grade using anti-PCNA/cyclin monoclonal antibodies in fixed, embedded tissues. Comparison with flow cytometric analysis. Am J Pathol 1989;134:733-9.

27. Mandir N, Englyst H, Goodlad RA. Resistant carbohydrates stimulate cell proliferation and crypt fission in wild-type mice and in the $\mathrm{Apc}(\mathrm{Min} /+)$ mouse model of intestinal cancer, association with enhanced polyp development. Br J Nutr 2008;100:711-21. https:// doi.org/10.1017/S0007114508901276

28. Yasui N, Sato M, Ochi T, Kimura T, Kawahata H, Kitamura Y, et al. Three modes of ossification during distraction osteogenesis in the rat. J Bone Joint Surg Br 1997;79:824-30. https://doi. org/10.1302/0301-620x.79b5.7423

29. Sodek J, Ganss B, McKee MD. Osteopontin. Crit Rev Oral Biol Med 2000;11:279-303. https://doi.org/10.1177/1045441100011003 0101

30. Standal T, Borset M, Sundan A. Role of osteopontin in adhesion, migration, cell survival and bone remodeling. Exp Oncol 2004;26:179-84.

31. Desbois C, Karsenty G. Osteocalcin cluster: implications for functional studies. J Cell Biochem 1995;57:379-83. https://doi. org $/ 10.1002 / j \mathrm{cb} .240570302$

32. Sato M, Yasui N, Nakase T, Kawahata H, Sugimoto M, Hirota S, et al. Expression of bone matrix proteins mRNA during distraction osteogenesis. J Bone Miner Res 1998;13:1221-31. https://doi. org/10.1359/jbmr.1998.13.8.1221

33. Sakamoto A, Oda Y, Iwamoto Y, Tsuneyoshi M. A comparative study of fibrous dysplasia and osteofibrous dysplasia with regard to expressions of c-fos and c-jun products and bone matrix proteins: a clinicopathologic review and immunohistochemical study of cfos, c-jun, type I collagen, osteonectin, osteopontin, and osteocalcin. Hum Pathol 1999;30:1418-26. https://doi.org/10.1016/s00468177(99)90162-4

How to cite this article: Sohn DS, Kim JR, Kim HG, Choi HS, Moon YS. Comparison of immunohistochemical analysis on sinus augmentation using demineralized tooth graft and bovine bone. J Korean Assoc Oral Maxillofac Surg 2021;47:269-278. https://doi. org/10.5125/jkaoms.2021.47.4.269 